\title{
A LINGUAGEM E A FORMAÇÃO DO SUJEITO MORAL NO DISCURSO SOBRE A DESIGUALDADE DE JEAN- JACQUES ROUSSEAU
}

\author{
Rodolfo de Souzal
}

\begin{abstract}
RESUMO: O artigo discute a necessidade de se pensar a formação do sujeito moral sob a perspectiva da análise da linguagem e suas implicações nos estudos sobre a função da retórica na política no Segundo Discurso de Jean-Jacques Rousseau. A concepção do homem natural auxilia na noção do sujeito moral e a narrativa sobre o estado de natureza revela-nos a tríade linguagem, língua e retórica. Sucessões que integram a concepção do homem como indivíduo com consciência de si mesmo, o início da sociedade civil ligado à ideia da propriedade e o estabelecimento da sociedade civil com o discurso "sedutor" do rico que propõe o pacto político. De um ser disperso no estado de natureza, o homem se constitui como sujeito moral que supõe o uso da linguagem. $\mathrm{O}$ sujeito moral também utiliza a língua de modo retórico ao propor o pacto político. Há conflitos entre moralidade, política e retórica?
\end{abstract}

Palavras-chave: sujeito moral; linguagem; natureza humana.

\begin{abstract}
The paper discusses the necessity of considering the formation of the moral subject from the perspective of the analysis of language and its implications for studies on the role of rhetoric in politics in the Second Speech by Jean-Jacques Rousseau. The conception of natural man assists in the notion of the moral subject, and his narrative about the state of nature reveals the triad of language, language and rhetoric. Sequences that are part of the conception of man as an individual with self-consciousness, the onset of civil society linked to the idea of property and the establishment of civil society discourse "seductive" the rich man who proposes the political pact. To be dispersed in a state of nature, man is constituted as a moral subject, which involves the use of language. The moral subject is also using the language of rhetorical mode in proposing the political pact. There are conflicts between morality, politics and rhetoric?
\end{abstract}

Key-words: moral subject, language, human nature.

"Nossas línguas são obra dos homens, e os homens são limitados. Nossas línguas são obra dos homens, e os homens são mentirosos."

(Rousseau, Carta a Christophe de Beaumont)

\footnotetext{
${ }^{1}$ Graduado em Filosofia pela Pontifícia Universidade Católica de Campinas. Pesquisa de Iniciação Científica orientada pela Profa ${ }^{a}$ Dra. Natalia Maruyama entre os anos de 2008 a 2009 com bolsa FAPIC/Reitoria. Artigo submetido em 21 de dezembro de 2010.
} 
Introdução

Rousseau redige o Discurso sobre a desigualdade para responder à questão proposta pela Academia de Dijon: "Qual é a origem da desigualdade entre os homens, e é ela autorizada pela lei natural?" Em resposta, ele propõe conjecturas sobre um estado de natureza hipotético no qual estaria a humanidade em sua origem. A partir da caracterização metafísica do homem, considerado como ser que possui uma vontade livre, o filósofo passa a elaborar uma ligação teórica do suposto estado puro de natureza até seu extremo contrário, o estado de sociedade. O emprego de hipóteses teóricas permite, então, ao autor demonstrar a origem da desigualdade existente entre os homens. No entanto, podemos notar que a estrutura desta ligação entre estado puro de natureza e estado de sociedade não se conduz de maneira linear. Nesse percurso da humanidade supõe-se haver diversos obstáculos. O problema consiste em localizar as razões que teriam levado os indivíduos dispersos no seio da natureza ao estabelecimento do pacto político. Como surgiram os laços de servidão entre o forte e o fraco? Em outros termos, como indaga o próprio autor: o que teria levado "o povo a comprar uma tranqüilidade imaginária pelo preço de uma felicidade real"? ${ }^{2}$ Estas são questões que Rousseau aborda de modo explícito em seu Segundo Discurso ${ }^{3}$.

Levando em consideração esse percurso da humanidade, e buscando as razões que nos permitem explicar a passagem do estado de natureza para o estado de sociedade, importa-nos ressaltar, ainda, uma questão fundamental, que se encontra de maneira implícita nessa obra e que pode ser formulada como se segue: Qual terá sido a importância da linguagem na formação do sujeito moral?

É inegável a importância da linguagem na evolução humana, tal como Rousseau a expõe no Discurso sobre a desigualdade. Vale lembrar que o autor empreende uma análise genealógica sobre a composição das línguas e suas modificações, sobre o surgimento da escrita, a "prosódia moderna" e sua relação com a música. Todo esse percurso é importante para a investigação acerca da formação do

\footnotetext{
2 J. J. ROUSSEAU, Discurso sobre a origem e os fundamentos da desigualdade entre os homens, p. 235. ${ }^{3}$ Antes de redigir o Discurso sobre a desigualdade, nos anos de 1754 e 1755, Rousseau havia publicado em 1750 o Discurso sobre as ciências e as artes, que foi premiado pela Academia de Dijon e consistia em responder à seguinte questão: "o restabelecimento das ciências e das artes terá contribuído para aprimorar os costumes?" O Discurso sobre as ciências e as artes é referido como Primeiro Discurso e o Discurso sobre a desigualdade, como Segundo Discurso.
} 
sujeito moral. Tais abordagens, Rousseau as explicita em determinadas passagens do Segundo Discurso e, principalmente, no Ensaio sobre a origem das línguas.

Ao destacar essas considerações concernentes à linguagem em geral, nossa investigação leva à constatação de que haveria, nessa filosofia genealógica de Rousseau, uma ênfase ainda não bem explicitada, nas interpretações de sua obra, que recai sobre a função da linguagem para o surgimento do homem como um sujeito moral. Essa constatação não se conduz propriamente pela via histórica, mas por uma concepção $a$ histórica ${ }^{4}$ da moralidade. Estamos diante, portanto, de uma genealogia que se dá fora do tempo propriamente histórico ${ }^{5}$. Genealogia que concerne aqui à origem da moralidade, tal como Rousseau a havia empregado na síntese de sua filosofia dirigida ao arcebispo de Paris, Christopher de Beaumont:

Mostrei que todos os vícios que se imputam ao coração humano não lhe são em absoluto naturais; fiz ver a maneira como nascem e, por assim dizer, segui sua genealogia, mostrando, como por uma contínua deterioração de sua bondade originária, os homens se tornam, enfim, o que são. ${ }^{6}$

A abordagem a-histórica desse percurso da humanidade e da evolução das ideias e princípios morais não se encontra unicamente no Discurso sobre $a$ desigualdade. A história hipotética dirige o Segundo Discurso, apontando para a origem da desigualdade, e aparece também no Ensaio sobre a origem das línguas, obra em que Rousseau expõe mais particularmente suas concepções concernentes ao surgimento da linguagem. Podemos comparar essas duas obras. No Segundo Discurso, como salienta J. Starobinski, Rousseau “insere uma história da linguagem no interior de uma história da

\footnotetext{
${ }^{4}$ Para realizar uma investigação livre dos enganos cometidos por outros filósofos, Rousseau considera todas as afirmações tratadas em seus Segundo Discurso como "raciocínios hipotéticos e condicionais, mais apropriados a esclarecer a natureza das coisas do que mostrar a verdadeira origem e semelhantes àquelas que todos os dias fazem nossos físicos sobre a formação do mundo" (op. cit., p. 236). Desse modo, Rousseau remete-nos a um tempo a-histórico, contido somente no livro da "natureza que jamais mente", para julgar o gênero humano. Assim, diz o autor: "Não constitui empreendimento trivial separar o que há de original e de artificial na natureza atual do homem, e conhecer com exatidão um estado que não mais existe, que talvez nunca tenha existido, que provavelmente jamais existirá, e sobre o qual se tem, contudo, a necessidade de alcançar noções exatas para bem julgar de nosso estado presente" (ibid., p. 227-228). Cf. toda essa passagem no Discurso sobre a desigualdade, p. 227-237.

5 Sobre a concepção de história no Segundo Discurso, ver V. GOLDSCHMIDT, Anthropologie et politique: les principes du système de Rousseau.

${ }^{6}$ J.-J. ROUSSEAU, Carta a Christopher de Beaumont, p. 21.
} 
sociedade; inversamente, o Ensaio [...] introduz uma história da sociedade no interior de uma história da linguagem."

Nossa exposição acerca da importância da linguagem para a formação do sujeito moral na filosofia de Rousseau divide-se em quatro partes. I) A linguagem e a concepção do eu. II) A língua e a concepção do meu. III) A retórica e a concepção do nosso. IV) Considerações conclusivas: o eu, o meu e o nosso. Nosso objetivo é chamar atenção para essa transição entre linguagem, língua e retórica, que ocorre paralelamente à passagem do isolamento primitivo para a formação da sociedade civil mediante o pacto político, passando pela formação da noção de propriedade. Esse percurso acompanha a caracterização da concepção de Rousseau sobre o ser humano, do momento em que este começa a sair do estado puro de natureza até sua formação como um sujeito moral.

\section{A linguagem e a concepção do eu}

Rousseau propõe uma concepção metafísica do homem no Discurso sobre a desigualdade. Começando por caracterizá-lo como ser livre e perfectível, é possível explicar as várias mudanças ocorridas em sua natureza. Não é, contudo, nessa perspectiva metafísica que o autor chama atenção para a importância da linguagem. A formação do sujeito moral se dá fora do estado puro de natureza e já supõe uma natureza humana modificada. Embora o homem do ponto de vista metafísico não se reduza àquele ser que vive em total isolamento, nessa obra importa mais ao autor caracterizá-lo a partir da concepção do homem original. Como sabemos, para Rousseau, o homem original é um ser amoral, assim como a bondade natural. Quando tratamos do sujeito moral não estamos mais, pois, no terreno do puro estado de natureza; tal ideia corresponde ao homem que abandonou a condição “invariável” desse estado originário.

O sujeito moral supõe uma natureza humana que difere de sua origem. É claro que, sendo um animal que possui a perfectibilidade - termo atribuído por Rousseau “à

\footnotetext{
${ }^{7}$ J. STAROBINSKI, Rousseau e a origem das línguas. In: Jean-Jacques Rousseau: a transparência e o obstáculo; seguido de setes ensaios sobre Rousseau, p. 310. Apesar da importância do tema, não pretendemos, neste texto, aprofundar as possíveis comparações entre essas duas obras de Rousseau, trabalho exaustivo que demanda mais análise e investigação.
} 
faculdade de aperfeiçoar-se" com o auxílio das circunstâncias ${ }^{8}$ - todas as modificações em sua natureza podem ser examinadas tendo-se como ponto de referência a concepção do homem original. Assim, podemos medir o grau de distanciamento do homem de seu estado primitivo. É o que faz Rousseau ao longo de toda a obra.

A perfectibilidade pode conduzir o homem tanto para o bem como para o mal. Este homem é um ser dotado de liberdade, qualidade que o faz aceitar ou não as necessidades que a natureza lhe impõe, e é, nas palavras do próprio autor, "sobretudo na consciência dessa liberdade que se mostra a espiritualidade de sua alma"9 , situação esta que não existe para os outros animais. Notemos, nessas mesmas passagens, que para Rousseau é essa consciência da liberdade, junto à perfectibilidade, que distingue o homem dos outros animais. Não há aqui referência à razão ou à linguagem como elemento distintivo. Ausência que não é casual, já que ele diz que não é tanto o entendimento, mas a qualidade de agente livre, que constitui a distinção específica do homem entre os animais. O homem é, como os outros animais, um ser que tem ideias mas, como nota Rousseau, essa qualidade só o "diferencia da besta pela intensidade."10

Quando nos dirigimos ao exame do sujeito moral no Segundo Discurso situamo-nos já no plano da perfectibilidade em ação, e não mais naquele estado de natureza inerte, que é chamado pelo próprio autor de puro estado de natureza. Devemos, então, considerar as características que distinguem o homem original do puro estado de natureza desse homem que vive supostamente no chamado estado de natureza histórico, onde há ação da perfectibilidade e, portanto, que supõe modificações na natureza humana. Salinas Fortes explana essa distinção entre o homem do estado histórico em oposição ao de natureza do seguinte modo:

Nesse [...] período, o homem ainda não atingiu o estado propriamente social, mas, já afastado do equilíbrio estático primitivo, resvalou para uma condição na qual é empurrado gradativamente para a sociedade. É o período que alguns comentadores propõem que se denomine estado de natureza histórico, que não deve ser confundido com o estado de natureza ${ }^{11}$

\footnotetext{
${ }^{8}$ J.-J. ROUSSEAU, Discurso sobre a origem e os fundamentos da desigualdade entre os homens, p. 243. 9 J.-J. ROUSSEAU, Discurso sobre a origem e os fundamentos da desigualdade entre os homens, p. 243.

${ }^{10}$ Ibid., p. 243.

11 L. R. S. FORTES, Rousseau: o bom selvagem, p. 60, grifo do autor. Não se trata aqui de uma contradição: podemos dizer que certos momentos da história hipotética do Segundo Discurso, por serem conjecturais, são a-históricos, no sentido de que se privilegia a estrutura e não o movimento ou os
} 
O afastamento deste homem do seu estado originário resulta de múltiplos fatores, entre eles a linguagem. Quanto mais se investiga o distanciamento do gênero humano do seu estado originário, mais notáveis são as modificações em seu modo viver ou de organizar a vida, assim como as modificações implicadas na aquisição de novas ideias, a construção de instrumentos, o uso da razão e a submissão das necessidades às paixões. Concebe-se pela análise a-histórica de Rousseau narrada tanto no Discurso sobre a desigualdade, como no Ensaio sobre a origem das línguas, a evidência do auxílio da linguagem como 'instrumento' indispensável para o alcance da situação social presente - o pacto político. $\mathrm{O}$ uso da linguagem emerge como algo imprescindível para a transmissão e ensinamento das conquistas adquiridas pelo homem $^{12}$, como para a difusão do uso do fogo, da agricultura, da educação ou para o “alargamento" e exercício da razão. Segundo o filósofo genebrino, esse instrumento permite que a espécie não se inicie do mesmo ponto, o que torna possível aos homens não serem eternas crianças ao longo dos séculos. A linguagem é também determinante para se pensar o pacto político.

Mas como terá surgido a linguagem e como esta contribuiu para o afastamento do homem do seu estado originário, no qual muito se assemelhava aos outros animais? Essas questões devem ser examinadas, pois têm grande relevância para que se possa compreender a importância da linguagem na formação do homem como um sujeito moral. Este é um homem que não se encontra preso aos princípios invariáveis do puro estado de natureza, um homem que possui perfectibilidade, liberdade e razão em exercício, para superar as dificuldades que a natureza lhe impõe ou para satisfazer novas necessidades que, por sua vez, são resultantes de seus novos atos.

A investigação acerca da origem da linguagem no Discurso sobre a desigualdade, permite constatar que Rousseau estabelece duas máximas. A primeira máxima consiste em dizer que, para que a linguagem se desenvolvesse, os homens não poderiam estar entregues ao puro estado de natureza, mas teriam que viver próximos e

eventos. Entretanto, quando nos referimos ao estado de natureza histórico, não queremos afirmar com isso que se trata de considerar outros sim aqueles fatos históricos que foram descartados mas, sim, que é preciso incorporar na concepção filosófica do estado de natureza de Rousseau dinamismo e movimento, possibilidade de mudanças, mudanças propiciadas pela ação da perfectibilidade.

12 J.-J. ROUSSEAU, Discurso sobre a origem e os fundamentos da desigualdade entre os homens, p. 215. 
necessitar uns dos outros. ${ }^{13}$ Todavia, foram necessários muitos anos e muito trabalho para que isso pudesse ocorrer, como salienta Rousseau: "pense-se nos trabalhos inimagináveis e no tempo infinito que custou a primeira invenção das línguas; juntem essas reflexões às precedentes e ter-se-á ideia de como foram precisos milhares de $\operatorname{anos}{ }^{14}$.

Antes de expor as convicções do filósofo sobre a origem das línguas, cabe destacar um problema inerente a esse ponto. A questão motriz do surgimento das línguas engendra-se de uma complicada causa. Trata-se aqui de uma indagação anterior àquela acerca da função da linguagem na formação do sujeito moral. A passagem do homem do estado puro de natureza para um estado em que suas características inatas encontram-se ativas ganha um elemento complicador, a interdependência entre a necessidade da linguagem e o uso do pensamento. Diz Rousseau:

\begin{abstract}
Pois, se os homens tiveram necessidade da palavra para aprender a pensar, tiveram muito mais necessidade ainda de saber pensar para encontrar a arte da palavra e, quando se chegasse a compreender como os sons da voz foram tomados como intérpretes convencionais de nossas ideias, ainda restaria por saber quais puderam ser os intérpretes dessa convenção para aquelas ideias que, não tendo de modo algum um objeto sensível, não se poderiam indicar nem pelo gesto, nem pela voz. ${ }^{15}$
\end{abstract}

Esse é um problema "espinhoso", e o próprio Rousseau o apresenta de modo aporético no Discurso sobre a desigualdade. Esse problema, o autor não soluciona em sua theoria exposta no Ensaio sobre a origem das línguas, tal como conclui M. Dascal. No artigo Linguagem e pensamento segundo Rousseau, Dascal expressa: "a doutrina a respeito da origem e desenvolvimento da linguagem apresentada no [...] [Ensaio] parece ignorar totalmente as objeções de princípio levantadas no [...] [Discurso]" ${ }^{\text {16 }}$. Segue-se que o problema da interdependência entre linguagem e pensamento permanece sem

\footnotetext{
13 “Que progresso poderia conhecer o gênero humano esparso nas florestas entre os animais? E até que ponto poderiam aperfeiçoar-se e esclarecerem-se [...] não tendo domicílio fixo nem necessidade uns dos outros [...]?” Cf. J.-J. ROUSSEAU, Discurso sobre a origem e os fundamentos da desigualdade entre os homens, p. 246.

${ }^{14}$ J.-J. ROUSSEAU, Discurso sobre a origem e os fundamentos da desigualdade entre os homens, p. 246.

15 J.-J. ROUSSEAU, Discurso sobre a origem e os fundamentos da desigualdade entre os homens, p. 247.

${ }^{16}$ DASCAL, Linguagem e pensamento segundo Rousseau, p. 51.
} 
solução, questão aberta, sem que o filósofo genebrino seja "culpado por não resolvêla."17

Esse problema relativo à complicada relação entre linguagem e pensamento não impede a construção de conjecturas sobre a origem das línguas. É possível apontar uma suposta origem para explicar como as línguas se formaram — seja pela necessidade do filho que expressa algo pelos sons à sua mãe ou, no sentido inverso, no caso em que a mãe transmite a seu filho a palavra. Ainda que tais hipóteses não resolvam esse problema "espinhoso" acerca da anterioridade entre linguagem e pensamento, tal obstáculo não impede a formulação, diz Rousseau, de "conjecturas toleráveis sobre o nascimento dessa arte de comunicar os pensamentos" ${ }^{\text {"18 }}$.

É nesse sentido que podemos concordar com Starobinski quando nota que, no Discurso sobre a desigualdade, Rousseau "insere uma história da linguagem no interior de uma história da sociedade." 19 Após superar, por assim dizer, a questão da anterioridade entre linguagem e pensamento, o genebrino expõe suas hipóteses acerca da origem da linguagem, tanto em seu Segundo Discurso, como em seu Ensaio. Assim, o homem sai do estado de natureza mediante o uso de suas faculdades e, supostamente, passa a viver próximo aos seus semelhantes. Essas são, notadamente, as duas condições necessárias para a existência da linguagem. Salinas Fortes ressalta:

\begin{abstract}
Imaginemos a ocorrência de grandes inundações ou tremores de terra que, ao mesmo tempo em que alteram as condições da vida na região, levam a uma nova correlação entre os homens. [...] Colocando obstáculos à sua sobrevivência e aproximando os homens uns dos outros, a catástrofe cósmica funcionaria como desencadeadora de todo o processo. Sob o estímulo dessas novas condições ambientais e em resposta a elas, o mecanismo da perfectibilidade foi acionado e os indivíduos encontraram a ocasião propícia para o despertar de suas potencialidades. ${ }^{20}$
\end{abstract}

Em certo momento da história hipotética, o homem só tem consciência de si devido ao princípio de auto-conservação e à piedade natural, ele desconhece seus semelhantes. Desse tipo de ocorrência posta pela natureza, tal como "os dilúvios

\footnotetext{
${ }^{17}$ Ibid., p. 68

18 J.-J. ROUSSEAU, Discurso sobre a origem e os fundamentos da desigualdade entre os homens, p. 247.

19 J. STAROBINSKI, Rousseau e a origem das línguas. In: Jean-Jacques Rousseau: a transparência e o obstáculo; seguido de setes ensaios sobre Rousseau, p. 310.

${ }^{20}$ FORTES, Rousseau: o bom selvagem, p. 59.
} 
particulares, os mares extravasados, as erupções dos vulcões, os grandes terremotos, os incêndios despertos pelo raio e que destroem as florestas" ${ }^{, 21}$, nas palavras do autor, junto ao respectivo exercício das faculdades necessárias para a superação desses obstáculos naturais, é engendrado ou, se preferirmos, desenvolve-se no homem o reconhecimento de si como um indivíduo. Não precisamos supor aqui nenhum outro tipo de causa determinando essas mudanças na natureza humana, já que, como notamos, é da qualidade específica do homem o reconhecer-se como tal, ao menos, se assim podemos interpretar a passagem sobre o homem metafísico, aquele cuja característica essencial reside na consciência da liberdade.

Essa é a concepção do $e u$, desenvolvimento que faz o homem se sobressair perante os outros animais; note-se que, no puro estado de natureza, o homem e os outros animais muito se assemelhavam, já que suas faculdades intelectuais são virtuais e não há situações em que ponha em ação efetivamente sua liberdade e sua perfectibilidade. Referente a essa passagem em que o homem desenvolve a consciência de si, destaca Rousseau:

\begin{abstract}
Assim, o primeiro olhar que lançou sobre si mesmo produziu-lhe o primeiro movimento de orgulho; assim, apenas distinguindo as categorias por considerar-se o primeiro por sua espécie, dispôs-se desde logo a considerarse o primeiro como indivíduo. ${ }^{22}$
\end{abstract}

Ainda a respeito dessa primeira e importante concepção do $e u$, cabe expor uma passagem em que Rousseau disserta sobre o desenvolvimento das crianças. Passagem que se encontra no Livro Primeiro de sua obra intitulada Emílio ou da educação. O filósofo expõe a seguinte observação sobre esse processo de transição que, em analogia com o Discurso sobre a desigualdade, relaciona-se com a imersão de um indivíduo consciente de si. Esse é o momento em que surge propriamente a noção do $e u$ :

Em crescendo, adquirimos forças, tornamo-nos menos inquietos, menos trêfegos, fechamo-nos mais em nós mesmos. A alma e o corpo põem-se, por assim dizer, em equilíbrio e a natureza não nos pede mais do que o movimento necessário à nossa conservação. Mas o desejo de mandar não se

\footnotetext{
${ }^{21}$ J.-J. ROUSSEAU, Ensaio sobre a origem das línguas, p. 180.

${ }^{22}$ Id., Discurso sobre a origem e os fundamentos da desigualdade entre os homens, p. 261.
} 
extingue com a necessidade que o fez surgir; o domínio desperta e satisfaz o amor próprio e o hábito o fortalece. Assim a fantasia sucede à necessidade, assim começam a arraigar-se os preconceitos da opinião. ${ }^{23}$

A partir de agora o homem não é mais guiado pela natureza, a não ser para satisfação das necessidades básicas. O homem torna-se efetivamente capaz de se identificar como um indivíduo, isto é, de reconhecer-se como um sujeito, o eu, e de reconhecer seu semelhante como um outro. Percebemos o outro como um indivíduo igual em espécie a nós mesmos; e percebemos ambos, o eu e o outro, como seres distintos dos outros animais pertencentes à natureza. Como conclui Rousseau sobre esse ponto de cisão, "conhecido o princípio, percebemos claramente o ponto em que abandonamos o caminho da natureza" 24 .

A linguagem, sob essas circunstâncias, surge como um instrumento de contrária função. Primeiro, ela contribui para o afastamento do homem do seu estado original e torna-se imprescindível para o estabelecimento da proximidade entre os vários indivíduos do gênero humano, proximidade que não existia no puro estado de natureza. Rousseau diz em seu Ensaio: "desde que um homem foi reconhecido por outro como um ser sensível, pensante e semelhante a ele próprio; o desejo ou a necessidade de comunicar-lhe seus sentimentos e pensamentos fizeram-no buscar meios para isso." 25 A necessidade de comunicação está, pois, presente desde o momento da descoberta do eu e do outro. O primeiro meio encontrado pelo homem para expressar-se a seu semelhante consistiu no "grito da natureza".

A primeira língua do homem, a língua mais universal, a mais enérgica e a única de que se necessitou antes de precisar-se persuadir homens reunidos, é o grito da natureza. Como esse grito só era proferido por uma espécie de instinto nas ocasiões mais prementes, para implorar socorro nos grandes perigos ou alívio nas dores violentas, não era de muito uso no curso comum da vida, onde reinam sentimentos mais moderados. ${ }^{26}$

\footnotetext{
${ }^{23}$ J.-J. ROUSSEAU, Livro Primeiro. In: Emílio, ou, da Educação, p. 49.

${ }^{24}$ Ibid., p. 49.

25 J.-J. ROUSSEAU, Ensaio sobre a origem das línguas, p. 159.

${ }^{26}$ J.-J. ROUSSEAU, Discurso sobre a origem e os fundamentos da desigualdade entre os homens, p. 248.
} 
Movido pelo instinto que envolve essa necessidade de comunicar-se com seu semelhante, o homem faz uso da linguagem. O gesto e a voz foram os primeiros meios de comunicação, tanto das necessidades ${ }^{27}$ quanto das paixões, e supõe-se que os homens já passavam a um estágio de "sociabilidade". Ao fazer uso dos sentidos, eles procuraram expor aos outros tanto o grito de prazer como o terrível grito de dor. Assim, por diversas partes da terra, os indivíduos do gênero humano, tornam-se condicionados a viver próximos uns dos outros, devido aos desastres que a natureza impusera. No Ensaio, Rousseau assim narra o momento de nascimento da linguagem: "não é a fome ou a sede, mas o amor, o ódio, a piedade, a cólera, que lhes arrancam as primeiras vozes [...], para emocionar um jovem coração, para repelir um agressor injusto, a natureza impõe sinais, gritos e queixumes. ${ }^{, 28}$

Dessa forma, observa-se a contribuição da linguagem para o afastamento do homem do seu estado de natureza. A linguagem tem importância fundamental para a constituição de ideias e para o "alargamento" da razão, sendo imprescindível para que emergisse no homem a consciência de si como um indivíduo. Assim, somente atrelada à linguagem é que podemos explicar como surgiu a concepção do eu. A linguagem contribui para o nascimento do homem como um eu que, posteriormente, transmuta-se em sujeito moral. Ela é, por conseguinte, determinante para explicarmos, não apenas seu afastamento do estado de natureza, mas também o início da moralidade e as primeiras associações.

\section{A língua e a concepção do meu}

Os homens livram-se da condição "invariável” da natureza e tornam-se cientes de sua própria existência como um $e u$. Da situação em que se encontravam dispersos pela terra, logo se juntam e concebem as primeiras famílias. É importante ressaltar que

\footnotetext{
${ }^{27}$ A "necessidade", aqui referida, consiste no que chamamos de "necessidade moral", que é o inverso de uma espécie de "necessidade natural". A necessidade moral surge mediante o abandono do homem do seu estado de natureza e, de modo contrário à "necessidade natural", faz com que os homens se aproximem ao invés de se espalharem. Sobre a distinção entre ambas as "necessidades", podemos recorrer às palavras de Rousseau: "O efeito natural das primeiras necessidades consistiu em separar os homens e não em aproximá-los. [...] Era preciso que assim acontecesse para que a espécie acabasse por esparramar-se e a terra se povoasse com rapidez, pois sem isso o gênero humano ter-se-ia amontoado num canto do mundo e todo o resto ficaria deserto." Cf. J.-J. ROUSSEAU, Ensaio sobre a origem das línguas, p.163, grifo nosso.

${ }^{28}$ J.-J. ROUSSEAU, Ensaio sobre a origem das línguas, p. 164.
} 
essa união não se dá simplesmente por um sentimento natural de solidariedade ou por algum amor pela humanidade. Como notava Rousseau, eles "não se ligavam por qualquer ideia de fraternidade comum e, possuindo como único árbitro a força, acreditavam-se inimigos uns dos outros.",29

Rousseau descarta a possibilidade de se explicar a origem das línguas a partir da associação familiar, quando afirma em uma nota de seu Ensaio: "as verdadeiras línguas absolutamente não possuem uma origem doméstica; somente uma convenção mais geral e mais duradoura pode estabelecê-las. ${ }^{, 30}$ Assim, nesse exame da a-história do Discurso sobre a desigualdade, cabem as seguintes questões: Quais foram os fatores que determinaram o aparecimento das línguas, mais complexas do que a simples comunicação pelos gestos e pelos gritos envolvidos na linguagem inicial empregada pelos homens? Qual é a importância da língua para a formação do sujeito moral, tal como podemos constatar a partir do exame do Discurso sobre a desigualdade?

Os gestos e os gritos são os efeitos das primeiras necessidades morais e das paixões. Contudo, as causas responsáveis pelo surgimento das línguas diversificam-se conforme as regiões ou territórios e suas condições climáticas. Em determinadas regiões não foram as paixões as principais fontes dos primeiros gestos e dos primeiros gritos empregados pelos homens e, sim, as necessidades de um alimento, a exigência de ajuda ou algum desprovimento. Assim, para Rousseau, "a principal causa que as distingue é o local, resultado dos climas em que nascem e da maneira pela qual se formam." ${ }^{31} \mathrm{O}$ filósofo alega que, para se compreender a origem das artes e dos costumes, basta observar os meios fornecidos pela natureza para que tais necessidades pudessem ser atendidas. O homem só aprende a pescar onde há rios, mares e condições propícias para seu exercício. O mesmo se pode concluir sobre os costumes. "Será, pois, também pelas mesmas causas que se deve explicar a diversidade das línguas e a oposição de seus caracteres. $" 32$ Ou seja, é também pelo clima e pela condição do ambiente que deve ser explicada a origem das paixões e necessidades que condicionam os gritos de prazer e de dor.

\footnotetext{
${ }^{29}$ J.-J. ROUSSEAU, Ensaio sobre a origem das línguas, p, p. 174-175.

${ }^{30}$ Ibid., p. 175, (Nota 37).

${ }^{31}$ Ibid., p. 174.

${ }^{32}$ Ibid., p. 179.
} 
Rousseau apresenta em seu Ensaio um exemplo da diferença entre a formação das línguas, conforme sejam constituídas no sul ou no norte da Europa. As regiões meridionais, onde os territórios são mais férteis devido à abundância de recursos naturais que podiam estar presentes e próximos às mãos dos homens (os alimentos, os rios ou mesmo os animais), foram os primeiros locais que escolheram para habitar. Em contrapartida, Rousseau alega que estas regiões foram as últimas nas quais se formou uma sociedade, devido à fraca necessidade que um homem sentia em relação ao outro. Mas o contato entre os homens era inevitável, embora nem sempre facilmente explicável. Se as necessidades da natureza não os forçavam a se auxiliarem mutuamente, o simples encontro do acaso aflorava as paixões e os reunia:

\begin{abstract}
As moças vinham procurar água para a casa, os moços para dar de beber aos rebanhos. Olhos habituados desde a infância aos mesmos objetos, começaram aí a ver outras coisas mais agradáveis. O coração emocionou-se com esses novos objetos, uma atração desconhecida tornou-o menos selvagem, experimentou o prazer de não estar só. ${ }^{33}$
\end{abstract}

Desse modo, Rousseau narra como as paixões uniram os homens nos climas amenos e férteis. É pelas paixões que as línguas nascem nessas regiões; são elas que põem os homens a viverem com seus semelhantes, cujas paixões os forçam a romperem os gestos e os gritos para comunicarem aos seus semelhantes seus sentimentos de prazer. Nota-se que esses semelhantes com os quais passam a conviver poderiam, antes, ser considerados como "inimigos". Assim, a família que anteriormente consistia na única relação dos homens que necessitavam da linguagem dos gestos e grunhidos, por meio das paixões estabelecem uma espécie de convenção com outras famílias nessas regiões, condição que Rousseau julgava ser essencial para a formação das línguas. ${ }^{34}$

Nas regiões do norte, o clima proporciona outros aspectos para a formação das línguas. O forte frio e a escassez dos alimentos são as condições predominantes nessas regiões e Rousseau expõe a seguinte observação sobre essa "cruel" condição na qual todos os povos setentrionais estão condicionados a viverem: "nesses tremendos climas, nos quais durante nove meses do ano tudo está morto, o sol aquece o ar durante poucas semanas, parecendo que o faz unicamente para dizer aos habitantes de que bens estão

\footnotetext{
${ }^{33}$ J.-J. ROUSSEAU, Ensaio sobre a origem das línguas, p. 183.

${ }^{34}$ Cf. nota 37 em: J.-J. ROUSSEAU, Ensaio sobre a origem das línguas, p. 175.
} 
privados" ${ }^{35}$ Logo, nessas frias regiões, não são as paixões que engendram as línguas e, sim, as necessidades que um homem possui do outro para o auxílio de sua própria sobrevivência. É assim que observa nosso filósofo:

Antes de pensar em viver feliz, tinha-se de pensar em viver. A sociedade só se formou pela indústria, porquanto a necessidade mútua unia muito mais os homens do que o teria feito o sentimento. Sempre presente, o perigo de perecer não permitia que se limitassem à língua do gesto, e entre eles a primeira palavra não foi amai-me, mas ajudai-me. ${ }^{36}$

Posto que as várias regiões proporcionam condições desiguais para o aparecimento das línguas, conseqüentemente, suas respectivas composições musicais são extremamente distintas. As línguas constituídas no sul são cantantes, acentuadas e vivas, visto que são "filhas" das paixões, como diz o autor do Ensaio. Elas tinham a finalidade de comover o coração alheio e de dizer: "amai-me" antes de qualquer coisa. Contudo, as línguas do norte possuem sua composição musical contrária às do sul. Ou seja, são claras e sem energia, cuja finalidade primordial destinava-se à clareza de dizerem: "ajudai-me" nos constantes momentos de penúria. ${ }^{37}$

Com base nisso, pode-se verificar que as línguas nos início eram limitadas e, depois, passaram por longos processos de desenvolvimento. Rousseau descreve todas essas sucessões de mudanças no seguinte trecho em seu Segundo Discurso:

\begin{abstract}
Quando as ideias dos homens começaram a estender-se e a multiplicar-se, e se estabeleceu entre eles uma comunicação mais íntima, procuraram sinais mais numerosos e uma língua mais extensa; multiplicaram as inflexões de voz e juntaram-lhes gestos que, por sua natureza, são mais expressivos e cujo sentido depende menos de uma determinação anterior. Exprimiram, pois, os objetos visíveis e móveis graças a gestos, e aqueles que atingem a audição, graças a sons imitativos; mas, como o gesto só indica os objetos presentes ou fáceis de serem descritos e as ações visíveis, como o gesto não é de uso universal, porquanto a obscuridade ou a interposição de um corpo o torna
\end{abstract}

\footnotetext{
${ }^{35}$ J.-J. ROUSSEAU, Ensaio sobre a origem das línguas, p. 184.

${ }^{36}$ J.-J. ROUSSEAU, Ensaio sobre a origem das línguas, p. 185. [Grifo do autor].

37 Tanto nos capítulos XI, XII, XIV, XV, XVI, XIX do Ensaio sobre a origem das línguas, como na Carta sobre a música francesa, Rousseau apresenta diversos exemplos sobre a diferença musical entre as línguas formadas no sul e no norte ao comparar seus resquícios nas línguas modernas como no francês e no italiano. Assim, Rousseau aponta as diferenças de acentuação, ritmo, harmonia, clareza e obscuridade a fim de expor tal distinção. Cf. J.-J. ROUSSEAU, Carta sobre a música francesa. Trad. José Oscar de Almeida Marques; Daniela de Fátima Garcia. Campinas: Unicamp - IFCH, 2005.
} 
inútil, e como o gesto mais exige do que excita a atenção, resolveram então substituí-lo pelas articulações da voz que sem ter a mesma relação com certas ideias são mais apropriadas a representá-las como sinais instituídos. ${ }^{38}$

Nessa passagem, Rousseau expõe como a linguagem dos gestos e os grunhidos convergiram em uma língua instituída pelo uso da voz. Uma vez que a linguagem dos sinais não era suficiente para representar os objetos que cercavam os homens de modo "universal", por meio da voz os homens encontraram um novo meio, mais "apropriado" para se comunicarem. A esse novo meio, Rousseau atribui à palavra "a primeira instituição social" 39. Isto é, a língua se constitui pela necessidade moral de um empreendimento comum dos homens de se comunicarem e reciprocamente de serem entendidos. Pelo uso comum dos mesmos sons, ainda dispersos pela terra, o gênero humano em determinadas regiões estabeleceram "regras implícitas" para o mesmo uso da palavra. Nesse sentido, Rousseau atribui à língua tanta importância quanto à primeira instituição social da humanidade.

Enquanto as paixões ou as necessidades designavam os homens a se aproximarem, quanto mais estes se aproximavam, mais se distanciavam de sua origem. A língua, exposta em sua origem, não deixa de ser um fator conseqüente para a formação do homem como sujeito, como também a linguagem fora em um período anterior para a concepção do $e u$. Sua influência se expressa nitidamente pela lógica que Rousseau expõe em seu Segundo Discurso, como no Ensaio. Assume-se que cada homem vivia em uma espécie de sociedade familiar, desvinculado de qualquer contato com seus semelhantes de outras partes e possuidor da linguagem dos gestos e grunhidos. Com o nascimento das línguas percebe-se o rompimento dessas condições e o "progresso" rumo ao estado de sociedade, que chega a uma situação contrária ao princípio originário dos homens, situação fundamental que sempre cabe ressaltar.

Entretanto, essa não é a maior participação da língua para o distanciamento do homem de sua origem. A língua ainda possui uma participação maior no Discurso sobre a desigualdade. Ela é importante, tal como indica Rousseau, para caracterizar o momento de nascimento da propriedade privada, que contribui para o primeiro passo

\footnotetext{
${ }^{38}$ J.-J. ROUSSEAU, Discurso sobre a origem e os fundamentos da desigualdade entre os homens, p. 248. [Grifo nosso].

${ }^{39}$ J.-J. ROUSSEAU, Ensaio sobre a origem das línguas, p. 159.
} 
rumo ao estado de sociedade. Sobre essa importante passagem do homem que antes nada possuía para uma nova condição, a do possuidor, diz o filósofo genebrino:

\begin{abstract}
O verdadeiro fundador da sociedade civil foi o primeiro que, tendo cercado um terreno, lembrou-se de dizer isto é meu e encontrou pessoas suficientemente simples para acreditá-lo. ${ }^{40}$
\end{abstract}

É nessa situação que o homem através da língua agrega as terras a si. O homem passa da identificação de si como um eu para a concepção de uma nova ideia, a do meu. Rousseau alega que essa nova ideia - o meu — não se desperta no homem de um momento para outro. Para que essa ideia tenha surgido em seu espírito foram necessárias outras inúmeras ideias. Esse é o ponto em que os membros do gênero humano se "acorrentam" uns aos outros. Mediante o uso da língua, empregada todavia de maneira "enganadora", o homem atribui a si mesmo um bem que deveria pertencer a todos, e tem aqui a fonte das suas desgraças. Essas desgraças são caracterizadas pelo autor, de modo mais específico, como "crimes, guerras, assassínios, misérias e horrores". ${ }^{41}$ Desgraças causadas pelos próprios homens e que poderiam ter sido evitadas pelo mesmo uso da língua. O uso da língua, nesse caso, seria libertador, e está suposto no momento em que alguém responde ao que propõe cercar um terreno e afirmar o meu. Teria evitado muita desgraça, nota Rousseau:

\begin{abstract}
Aquele que, arrancando as estacas ou enchendo o fosso, tivesse gritado a seus semelhantes: "Defendei-vos de ouvir esse impostor; estareis perdidos se esquecerdes que os frutos são de todos e que a terra não pertence a ninguém!" 42
\end{abstract}

Entretanto, esse recurso da linguagem como contra argumento caracteriza uma possibilidade que não parece ter se firmado na história hipotética da humanidade. Todas as desgraças que poderiam ter sido evitadas se concretizaram, como Rousseau as descreve na hipotética exposição do percurso humano na Segunda Parte de seu Discurso sobre a desigualdade. Aqueles homens que nada possuíam não combateram o

\footnotetext{
${ }^{40}$ Id., Discurso sobre a origem e os fundamentos da desigualdade entre os homens, p. 259, grifo do autor.

${ }^{41}$ J.-J. ROUSSEAU, Discurso sobre a origem e os fundamentos da desigualdade entre os homens, p. 259.

${ }^{42}$ Ibid., p. 259.
} 
ato da apropriação dos homens que cercaram um terreno. Segundo Rousseau, sucedeuse o contrário, "acharam mais rápido e seguro imitá-los do que tentar desalojá-los". 43

Assim, respondemos à questão acerca da importância da língua para a formação do sujeito moral. O claro emprego da língua pelos homens não deixa dúvida sobre sua importância para o desenvolvimento da moralidade. Os homens, com auxílio da linguagem, se reconhecem como indivíduos, o eu. Logo, o advento das línguas regidas por "regras implícitas", devido às condições que as regiões impõem às necessidades ou as paixões, contribui para a efetiva aproximação dos homens e para o surgimento da propriedade privada com a concepção da ideia do meu. Cabe ressaltar que, para o surgimento dessas ideias, a do eu e a do meu, tem-se considerado a superação da "espinhosa" interdependência existente entre linguagem e pensamento, como foi citado anteriormente. Problema que, segundo Dascal, Rousseau expõe em seu Segundo Discurso de modo aporético, mas não o resolve.

No estado de natureza, como afirma Rousseau, o homem possuía como seus únicos bens a alimentação, a fêmea e o repouso, e como seus únicos males, a dor e a fome $^{44}$. Com a nova ideia do $m e u$, essas condições "naturais" não lhe serão mais suficientes. Tais condições, que poderiam conferir ao homem no estado puro de natureza uma espécie de felicidade, no estado aqui descrito, em que surge a noção do meu, tornam-se insuficientes para o bem-estar humano. Assim, pode-se dizer que a língua proporciona uma nova posição na concepção geral que se tem do homem, diferente da anterior concepção, que se apoiava simplesmente na ideia do $e u$. Com o surgimento da ideia do meu, e mediante sua origem e condição, assistimos ao movimento do homem rumo ao estado de sociedade.

\section{A retórica e a concepção do nosso}

Com a introdução da ideia de propriedade - e a noção do meu - o gênero humano se conduziu a passos largos, ao contrário do que ocorria no estado puro de natureza, que era estático. Como expõe Rousseau, em um determinando momento, homens se apropriaram das terras, construíram cabanas, apossaram-se das árvores e dos

\footnotetext{
${ }^{43}$ Ibid., p. 262.

${ }^{44}$ J.-J. ROUSSEAU, Discurso sobre a origem e os fundamentos da desigualdade entre os homens, p. 244.
} 
frutos que antes pertenciam a todos. Aqui já há algum tipo de associação entre os homens. Nessas sociedades iniciadas, os membros da espécie humana passaram a se reunir, depois a estabelecer alguns tipos de relações morais que anteriormente desconheciam. A simples linguagem dos gestos e dos gritos não é mais suficiente. Elabora-se uma língua de entendimento comum. Com efeito, os homens não possuem apenas a ideia do $e u$, mas também possuem a ideia de posse, do meu.

Acompanhemos o percurso dos homens, ainda no estado de natureza, mais particularmente no momento em que eles começam a adquirir alguma noção de propriedade. Fixos em um único lugar, nota Rousseau, "começaram a cultivar a volta de sua cabana alguns legumes ou raízes" 45 . Com o passar dos séculos, foram civilizados pelo ferro e pelo trigo ${ }^{46}$. Muitas mudanças, portanto, ocorreram. Importa-nos ressaltar que, após a formação das instituições civis, a desigualdade entre os homens aumentava drasticamente. Os mais fortes trabalhavam mais, os mais habilidosos se sobressaíam perante seus semelhantes, os mais engenhosos construíam meios para obterem cada vez mais. Em outros termos, como nota o autor, enquanto "um ganhava muito [...] outro tinha dificuldade de viver" ${ }^{\prime 7}$. Como conseqüência, a desigualdade física, junto a algumas atividades que já supunham certa convenção entre os homens, contribuiu de certo modo para a instauração progressiva da desigualdade.

Com o estabelecimento de novas relações entre os participantes dessas convenções gerais e, sucessivamente, com as mudanças ocorridas no que concerne a seus bens, chega-se a um momento em que alguns prosperam com o prejuízo de outros. O que ocorre, paralelamente, com o sujeito moral? Alega Rousseau que dessa situação começam a nascer "segundo os vários caracteres de uns e de outros, a dominação e a servidão, ou a violência e os roubos." ${ }^{48}$ Nesse longo período das primeiras convenções, a piedade natural é suprimida diante das paixões desenfreadas. Assim também ocorre com a ideia de justiça que, logo que se forma na mente humana, já se torna fraca. Como pensarmos aqui o sujeito moral? Com as associações, nasce a moralidade, mas os homens se tornam maus e ambiciosos, buscando satisfazer seus próprios prazeres, mais

\footnotetext{
${ }^{45}$ Ibid., p. 265.

${ }^{46}$ Ibid., p. 265. Embora o termo civilização receba ao longo da história do pensamento ocidental sentidos diferentes, não pretendemos aqui examinar mais profundamente o uso da expressão civilizar, tal como aparece nessa passagem da obra, "o ferro e o trigo civilizaram os homens".

47 J.-J. ROUSSEAU, Discurso sobre a origem e os fundamentos da desigualdade entre os homens, p. 266.

${ }^{48}$ Ibid., p. 268.
} 
do que atender às necessidades de seus semelhantes. Cabe ressaltar que essas sociedades iniciadas são estabelecidas pelos costumes e pela moralidade entre seus membros, onde cada homem é seu próprio "juiz e vingador das ofensas que recebia" filósofo.

As mudanças no modo de organização de vida e na condição do homem nesse estágio da história hipotética derivam, pois, em parte, da desgraça alheia. Assim, segundo Rousseau, "a sociedade nascente foi colocada no mais tremendo estado de guerra" ${ }^{50} \mathrm{O}$ homem possui nesse momento a ideia do meu, aquilo que atende o princípio da auto-conservação não é mais suficiente para a sua felicidade, em razão de que, além de si mesmo, cabe preservar seus bens para seu bem-estar. No entanto, nessa condição delicada em que se encontrava o gênero humano, um grave problema se instaura, em razão de que existiam conquistados e conquistadores, cujas polaridades poderiam inverter-se constantemente, provocando um estado generalizado de guerra, sem que nenhum dos lados jamais deixasse de combater em nome de seus interesses particulares.

Neste ponto Rousseau reencontra Hobbes ${ }^{51}$. Como seria possível colocar fim a uma guerra sem o próprio uso da força? Pode-se constatar no Discurso sobre a desigualdade que, nessa situação em que se encontra o gênero humano, Rousseau apresenta o uso da língua como um ‘instrumento’ decisivo que coloca fim a essa guerra. Destacamos aqui, no momento de elaboração da ideia do pacto político, o ápice do uso da língua. O constante estado de guerra não é uma condição que favorece aqueles que possuem mais bens, pois esses arcam com os maiores prejuízos. Essa deveu ser a constatação dos "ricos" 52 que, como salienta Rousseau, "logo perceberam quanto lhes

\footnotetext{
${ }^{49}$ Ibid., p. 264.

${ }^{50}$ Ibid., p. 268.

51 Guardadas as devidas diferenças entre as concepções da natureza humana e do pacto político em Hobbes e em Rousseau, podemos notar que, para ambos, tratava-se de colocar fim à situação de conflito em que se encontrava a humanidade antes do estabelecimento do poder político, das leis e dos governos. Para um estudo mais amplo da relação teórica entre os dois autores, cf. o livro de R. DÉRATHÉ, JeanJacques Rousseau et la science politique de son temps. Paris: Libraire Philosophique J, Vrin, 1995.

52 Rousseau expõe os homens ricos na segunda parte do Discurso sobre a desigualdade como homens mais elevados tanto pela quantidade de bens que possuem quanto pelo melhor uso da língua, já que são eles que empregam a língua de modo retórico para defender seus interesses contra seus inimigos. A defesa de seus interesses com a proposta do pacto político é, pois, integrada ao texto de Rousseau no momento de expor as razões dessa convenção que deve colocar fim ao estado de guerra generalizado.
} 
era desvantajosa uma guerra perpétua cujos gastos só eles pagavam e na qual tanto o risco da sua vida como a dos bens particulares eram comuns.",53

Diante dessa grande dificuldade, de colocar fim à situação de conflito sem expor a própria vida e, ao mesmo tempo, de buscar, ainda, conservar suas posses, os ricos utilizaram a língua em um discurso retórico para preservar o que possuíam. Entretanto, eles não recorreram simplesmente a um uso comum da língua, pois perceberam que aquela simples proposição quando se diz "isto é meu", ou ainda a argumentação sustentada na mera posse justificada pelo trabalho implícita na afirmação "fui eu quem construiu este muro; ganhei este terreno com meu trabalho" ${ }^{54}$, não era suficiente para convencer seus semelhantes. Se até o momento era suficiente uma simples ideia, como havia ocorrido anteriormente por ocasião do nascimento da ideia do $m e u$, momento em que era fixada em uma única expressão a ideia da propriedade privada, agora, para resolver os conflitos seria preciso de um discurso mais elaborado. Tratava-se de "persuadir homens reunidos". Os ricos necessitavam mais do que o simples emprego da língua para persuadir seus semelhantes a não atacá-los. Dizer “isto é meu" não bastava, pois, em defesa de seus interesses, outros homens poderiam combatê-los com o seguinte argumento:

\begin{abstract}
Quem vos deu as demarcações, por que razão pretendeis ser pagos a nossas expensas, de um trabalho que não vos impusemos? Ignorais que uma multidão de vossos irmãos perece e sofre a necessidade do que tendes a mais e que vos seria necessário um consentimento expresso e unânime do gênero humano para que, da subsistência comum, vos apropriásseis de quanto ultrapassasse a vossa? ${ }^{55}$
\end{abstract}

Aquele contra argumento que poderia ter sido lançado por ocasião da fixação da noção de propriedade privada ${ }^{56}$ poderia, agora, concretizar-se, em razão de que todos os homens possuíam de modo mais claro e efetivo interesses comuns. Todos poderiam unir-se, voltando-se contra aqueles que pretendiam legitimar suas posses e, por consequiência, estabelecer com auxílio das leis a desigualdade. O combate fora evitado

\footnotetext{
53 J.-J. ROUSSEAU, Discurso sobre a origem e os fundamentos da desigualdade entre os homens, p. 268.

${ }^{54}$ Ibid., p. 268.

55 J.-J. ROUSSEAU, Discurso sobre a origem e os fundamentos da desigualdade entre os homens, p. 268.

56 "Defendei-vos de ouvir esse impostor; estareis perdidos se esquecerdes que os frutos são de todos e que a terra não pertence a ninguém!”. Cf. J.-J. ROUSSEAU, Discurso sobre a origem e os fundamentos da desigualdade entre os homens, p. 259.
} 
entre homens fracos e fortes no momento em que começou a surgir a propriedade, visto que cada homem preferiu apossar-se dos bens que não fora designado como meu e, assim, ocupar um local desabitado ${ }^{57}$. Notemos que, nesse caso, aquilo que não tinha "dono" deixaria de existir. Se os ricos, ou seus opositores, quisessem progredir em expansão de posses e adquirir novos bens, o combate para tal conquista seria então inevitável.

Apesar do uso da força aparentar ser a única via para se alcançar a paz entre o gênero humano, esse não foi o modo empregado para tal propósito. Com foi citado anteriormente, Rousseau atribui o fim dessa deplorável situação ao uso da palavra, isto é, o uso da língua como artifício de retórica. Os ricos utilizam o discurso para definir as coisas da maneira como desejavam que seus semelhantes as vissem. Por meio do uso retórico da língua, suposto aqui na elaboração dessa estrutura complexa que é o pacto político, os ricos convencem seus semelhantes a porem fim à guerra generalizada sem que precisassem empregar a força física. ${ }^{58}$

Rousseau concebe, portanto, o fim da guerra generalizada a partir de uma reflexão acerca do uso do discurso retórico. Os ricos teriam elaborado esse discurso, dirigindo-o aos seus semelhantes, para preservarem seus próprios interesses, pois dizer “isto é meu” não bastava mais para esse propósito. Este é o discurso proferido pelo rico exposto no Segundo Discurso:

"unamo-nos", disse-lhe, "para defender os fracos da opressão, conter os
ambiciosos e assegurar a cada um a posse daquilo que lhe pertence;
instituamos regulamentos de justiça e de paz, aos quais todos sejam
obrigados a conformar-se, que não abram exceção para ninguém e que,
submetendo igualmente a deveres mútuos o poderoso e o fraco, reparem de
certo modo os caprichos da fortuna. Em uma palavra, em lugar de voltar
nossas forças contra nós mesmos, reunamo-nos num poder supremo que nos

57 "No entanto, como os mais fortes possivelmente foram os primeiros a fazer habitações que se sentiam capazes de defender, é de crer que os fracos acharam mais rápido e seguro imitá-los do que tentar desalojá-los e, quanto aos que já possuíam cabanas, nenhum deles certamente procurou apropriar-se da de seu vizinho, menos por não lhe pertencer do que por ser-lhe inútil e não poder apossar-se dela sem exporse a um combate violento com a família ocupante." Cf. J.-J. ROUSSEAU, Discurso sobre a origem e os fundamentos da desigualdade entre os homens, p. 262.

${ }_{58}$ Rousseau elimina três possíveis formas da constituição do pacto político em defesa do uso da língua empregada de modo retórico para colocar fim ao estado generalizado de guerra. Eis as possibilidades afastadas pelo filósofo: $1 .^{\circ}$ a ideia do contrato social sustentada no direito de conquista; $2 .^{\circ}$ explicação do pacto político por meio das palavras forte e fraco; $3 .^{\circ}$ contrato social estabelecido renunciando-se à liberdade. Cf. J.-J. ROUSSEAU, Discurso sobre a origem e os fundamentos da desigualdade entre os homens, p. 270-271. 
governe segundo sábias leis, que protejam e defendam todos os membros da associação, expulsem os inimigos comuns e nos mantenham em concórdia eterna". 59

Desta maneira, todos os ouvintes do presente discurso foram "seduzidos". Foram todos "acorrentados", como destaca Rousseau, tanto pela inocência, pela malícia, como pela falta de reflexão diante de tal discurso. Foram "seduzidos" pela falsa aparência, em razão de que acreditavam assegurar sua liberdade, "pois, como nota o autor, com muita razão reconhecendo as vantagens de um estabelecimento político, não contavam com a suficiente experiência para prever-lhe os perigos" ${ }^{\prime 60}$. Mesmo os homens "prudentes", que poderiam ser capazes de reconhecer os "grilhões" de sua liberdade, entregaram-se ao erro por acreditarem ser esta a melhor situação ao invés de combatêla.

Desta proposta proferida pelos ricos - "unamo-nos", concebe-se a nova ideia do nosso, curiosamente, em certa oposição à ideia do meu. Observa-se, contudo, que, tanto em relação à concepção do meu, como em relação à ideia do nosso, não houve resistência, um possível contra argumento constituindo-se apenas como uma hipótese improvável diante da situação real de conflito e desigualdade. Ou seja, não existiu na formação do pacto político, como na fixação da noção da propriedade privada, um argumento efetivo exposto no Discurso sobre a desigualdade em oposição às concepções do meu e do nosso. Com a inexistência desse contra argumento, a língua passa a ser empregada, com a constituição do pacto político, para defender os bens e interesses de alguns indivíduos. Ela passou da concepção da ideia do meu para a apropriação real de bens. Com o uso retórico da língua, temos numa história hipotética da linguagem um 'instrumento' para a preservação da propriedade privada. Mas, nessa história hipotética do Segundo Discurso, que lugar devemos reservar à nova ideia do nosso.

Com a ideia do nosso os homens passam a uma nova posição no Discurso sobre a desigualdade, visto que cada indivíduo abandona, por assim dizer, sua "liberdade natural", já que não é mais independente em relação aos outros, para submeter-se aos deveres comuns impostos por um pacto político. Antes do pacto

\footnotetext{
${ }^{59}$ J.-J. ROUSSEAU, Discurso sobre a origem e os fundamentos da desigualdade entre os homens, p. 269.

${ }^{60}$ Ibid., p. 269.
} 
político, o homem vivia em uma associação espontânea e agia apenas por uma convenção moral, tácita, sem regras nem leis estabelecidas claramente. O único juiz de suas ações era ele mesmo, o próprio indivíduo, autor dos atos cometidos. Depois do pacto político, esse indivíduo passa a ser um homem civil, policiado, que deve se submeter às leis políticas instituídas pelo acordo comum. Essas leis estabelecidas e fundadas pela ideia do pacto político transformam aquela sociedade, que antes era espontânea, em uma sociedade política, com um poder comum. Em analogia com essas considerações acerca da constituição do pacto político no Discurso sobre a desigualdade, Rousseau, em uma singular passagem do Emílio, descreve da seguinte maneira a função do pacto político sobre seus adeptos:

As boas instituições sociais são as que mais bem sabem desnaturar o homem, tirando-lhe sua existência absoluta para dar-lhe outra relativa e colocar o eu na unidade comum, de modo que cada particular não se acredite mais ser um, que se sinta uma parte da unidade, e não seja mais sensível senão no todo. ${ }^{61}$

Com a consolidação do pacto, tanto a ideia do $e u$, quanto a do meu, convergem para a ideia do nosso. Sujeito moral, indivíduo proprietário e membro da comunidade política parecem reunir-se no final do Segundo Discurso. A ideia do nosso sobrepõe-se à unidade pressuposta nas ideias do $e u$ e do meu e instaura por definitivo "regras positivas", que anteriormente eram apenas tomadas como "regras implícitas". Desse uso comum de uma mesma língua, a partir de normas e regras implícitas e espontâneas, passamos com a ideia do nosso a considerar um discurso retórico, com suas funções estratégicas de persuasão. Assim, nessa última 'instrumentalização' da língua, referida no Discurso sobre a desigualdade, temos a linguagem empregada de modo retórico, convertendo o sujeito moral em um cidadão, homem civil, membro de uma comunidade política. Este é o ápice de um estágio da humanidade que se opõe ao estado de natureza, como conclui Rousseau em resposta à Academia de Dijon.

\footnotetext{
${ }^{61}$ J.-J. ROUSSEAU, Livro Primeiro. In: Emílio, ou, da Educação, p. 13, grifo do autor.
} 


\section{Considerações conclusivas: $o$ eu, o meu $e$ o nosso}

O exame exaustivo destes três pontos - o eu, o meu e o nosso - permite circunscrever o papel da linguagem como fator imprescindível para a formação do sujeito moral e do cidadão. Esta é a constatação que o presente artigo se propôs expor de modo a ressaltar três momentos da história hipotética da linguagem que é possível apreender com a leitura rigorosa do Discurso sobre a desigualdade. A linguagem surge como 'instrumento' crucial para o primeiro distanciamento do homem do seu estado de natureza, afastamento que é proporcionado primeiramente pela concepção do homem como um reconhecedor de si mesmo, um eu. Esse homem, contrariamente ao seu estado anterior, é capaz de reconhecer também seus semelhantes e de conceber novas ideias. Aquela "espinhosa" circularidade entre linguagem e pensamento, referida pelo autor, pode ser pensada aqui como sendo aquilo mesmo que constitui substancialmente a relação entre linguagem e sujeito. As novas ideias que surgem com as primeiras associações e a formação do homem enquanto sujeito moral são expressas tanto pelos gestos como pelo uso da voz. Rousseau parece enfatizar em seu texto, embora sem excluir o aspecto paradoxal do problema, que o uso da linguagem aproximou o gênero humano que se encontrava disperso pela terra naquele suposto estado puro de natureza. A contribuição da linguagem para a formação da concepção do $e u$ é, nesse sentido, passo importante em direção à formação do sujeito moral, podendo até mesmo ser considerada como a condição em que a moralidade se torna possível.

A língua advém, portanto, como a principal via para o estabelecimento da comunicação entre os homens e, também, para a construção da concepção do meu. Pela língua os homens estabeleceram regras implícitas para o uso comum da palavra, por meio das qual todos poderiam falar e serem ouvidos. Esses efeitos do uso da língua é que os aproximaram e os condicionaram a viver com auxílio de uma convenção. Isso não basta. Ainda, como notamos, por meio da língua, novas ideias emergiram no espírito humano, entre elas, a ideia de propriedade, a ideia do meu. Por meio destas, como afirma Rousseau, funda-se a sociedade civil. Uma vez tendo iniciado todo esse processo, a espécie humana encontrava-se posta em um novo ponto de sua história, como o filósofo genebrino expõe em sua a-história sobre a desigualdade humana. Com o exame da ideia do meu percebe-se, então, o importante papel exercido pela língua, que afasta o homem de sua origem, deixando de ser aquele ser que nada possuía - o meu. 
Nessa situação do estado puro de natureza, em que nada possuía, ele tampouco se reconhecia - o eu.

Ameaçados pelas constantes guerras provocadas por interesses divergentes, esses homens, que já estavam dotados de moralidade, passam a empregar a linguagem em um discurso retórico. Assim, uniram-se para colocar fim a essa guerra, o que só foi possível com a consolidação do pacto político. A constituição do pacto político marca o momento da história da humanidade em que não existe apenas a ideia do meu, mas emerge sob total acordo uma nova ideia, a ideia do nosso.

A ideia do nosso vem para acabar com o estado de guerra. Portanto, essa guerra de interesses que assolava o gênero humano extingue-se pelo uso da palavra. O pacto político assegura, desse modo, a paz e, concomitantemente, o que cada indivíduo possui ou pretende possuir. O nosso de Rousseau parece não contradizer o meu. Ao menos é a essa conclusão que nos permite chegar o Discurso sobre a desigualdade.

Esta análise permitiu-nos apontar de modo abrangente a relevância da linguagem na formação do sujeito moral e da comunidade política. Destacamos ao longo deste estudo a transição entre linguagem, língua e retórica, transição que supõe a passagem sucessiva pela concepção do $e u$, pela ideia de posse com a concepção do meu e, por fim, pela constituição do pacto político, com o estabelecimento da sociedade política e o surgimento da ideia do nosso. Esperamos ter exposto tão claramente a interpretação acerca da importância da linguagem no Discurso sobre a desigualdade para a formação do sujeito moral. Talvez se torne, agora, mais compreensível o significado da primeira frase de Rousseau no Ensaio sobre a origem das línguas: "a palavra distingue os homens entre os animais; a linguagem, as nações entre si - não se sabe de onde é um homem antes de ter ele falado."

Poderíamos ainda completar, "o uso da linguagem distingue as etapas da história da humanidade - não se sabe o que é o homem antes de ter ele empregado a linguagem".

\footnotetext{
${ }^{62}$ J.-J. ROUSSEAU, Ensaio sobre a origem das línguas, p. 159.
} 


\section{Bibliografia}

DASCAL, Marcelo. Linguagem e pensamento segundo Rousseau. Manuscrito: Revista de Filosofia, Campinas, UNICAMP, v. 3, n. 2, p. 51-70, abr. 1980.

DÉRATHÉ, Robert. Jean-Jacques Rousseau et la science politique de son temps. Paris: Libraire Philosophique J, Vrin, 1995.

FORTES, Luiz Roberto Salinas. Rousseau: o bom selvagem. São Paulo: FTD, 1989. (Col. Prazer em conhecer)

GOLDSCHMIDT, Victor. Anthropologie et politique: les principes du système de Rousseau. Paris: Vrin, 1983.

HOBBES, Thomas. Leviatã ou Matéria, Forma e Poder de um Estado Eclesiástico e Civil. Trad. João Paulo Monteiro; Maria Beatriz N. da Silva. São Paulo: Abril Cultural, 1974. (Os pensadores)

MARUYAMA, Natalia. A contradição entre o homem e o cidadão: consciência e política segundo J.-J. Rousseau. São Paulo: Humanitas; Fapesp, 2001.

PRADO JÚNIOR, Bento; MATTOS, Franklin (org.). A retórica de Rousseau e outros ensaios. São Paulo: Cosac Naify, 2008.

ROUSSEAU, Jean-Jacques. Carta a Christopher de Beaumont. Trad. José Oscar de Almeida marques. Campinas: Unicamp - IFCH, 2004. (Clássicos da filosofia: Cadernos de tradução n. 8)

Carta sobre a música francesa. Trad. José Oscar de Almeida marques; Daniela de Fátima Garcia. Campinas: Unicamp - IFCH, 2005. 48 p. (Textos didáticos $\left.n^{\circ} 58\right)$

. Discurso sobre a origem e os fundamentos da desigualdade entre os homens. Trad. Lourdes Santos Machado. 2. Ed. São Paulo: Abril Cultural, 1978. (Os pensadores) 
Emílio; ou, Da educação. Trad. Sérgio Milliet. 3. Ed. Rio de Janeiro: Bertrand Brasil, 1995.

. Ensaio sobre a origem das línguas. Trad. Lourdes Santos Machado.

2. ed. São Paulo: Abril Cultural, 1978. (Os pensadores)

STAROBINSKI, Jean. Rousseau e a origem das línguas. In. Jean-Jacques Rousseau: a transparência e o obstáculo; seguido de setes ensaios sobre Rousseau. Trad. Maria Lúcia Machado. São Paulo: Companhia das Letras, 1991. 